Anton Pannekoek: Ways of Viewing Science and Society 


\section{Studies in the History of Knowledge}

This book series publishes leading volumes that study the history of knowledge in its cultural context. It aspires to offer accounts that cut across disciplinary and geographical boundaries, while being sensitive to how institutional circumstances and different scales of time shape the making of knowledge.

\section{Series Editors}

Klaas van Berkel, University of Groningen

Jeroen van Dongen, University of Amsterdam 


\title{
Anton Pannekoek: Ways of Viewing Science and Society
}

\author{
Edited by \\ Chaokang Tai, Bart van der Steen, and Jeroen van Dongen
}


Cover illustration: (Background) Fisheye lens photo of the Zeiss Planetarium Projector of Artis Amsterdam Royal Zoo in action. (Foreground) Fisheye lens photo of a portrait of Anton Pannekoek displayed in the common room of the Anton Pannekoek Institute for Astronomy. Source: Jeronimo Voss

Cover design: Coördesign, Leiden

Lay-out: Crius Group, Hulshout

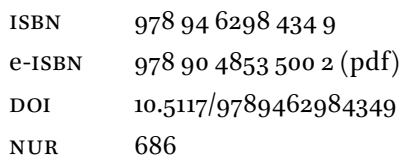

Creative Commons License CC BY NC ND (http://creativecommons.org/licenses/by-nc-nd/3.o)

@ The authors / Amsterdam University Press B.V., Amsterdam 2019

Some rights reserved. Without limiting the rights under copyright reserved above, any part of this book may be reproduced, stored in or introduced into a retrieval system, or transmitted, in any form or by any means (electronic, mechanical, photocopying, recording or otherwise). 